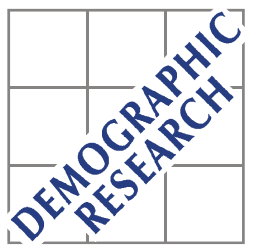

Demographic Research a free, expedited, online journal of peer-reviewed research and commentary in the population sciences published by the Max Planck Institute for Demographic Research Konrad-Zuse Str. 1, D-18057 Rostock · GERMANY www.demographic-research.org

DEMOGRAPHIC RESEARCH

VOLUME 25, ARTICLE 15, PAGES 491-512 PUBLISHED 19 AUGUST 2011

http://www.demographic-research.org/Volumes/Vol25/15/

DOI: 10.4054/DemRes.2011.25.15

Research Article

\title{
Demographic responses to short-term stress in a 19th century Tuscan population: The case of household out-migration
}

\section{Marco Breschi}

\section{Matteo Manfredini}

\section{Alessio Fornasin}

(C) 2011 Marco Breschi, Matteo Manfredini \& Alessio Fornasin.

This open-access work is published under the terms of the Creative Commons Attribution NonCommercial License 2.0 Germany, which permits use, reproduction \& distribution in any medium for non-commercial purposes, provided the original author(s) and source are given credit. See http:// creativecommons.org/licenses/by-nc/2.0/de/ 


\section{Table of Contents}

1 Introduction 492

2 Household out-migration. The Tuscan dichotomy:

Sharecroppers and day laborers 493

$3 \quad$ Sources, data, and the method used 496

$4 \quad$ The parish of Casalguidi. Social structure and household out-migration $\quad 498$

$5 \quad$ Causes of household emigration. Role of different short-term stresses and differential responses by SES 501

$\begin{array}{lll}6 & \text { Conclusions } & 509\end{array}$

$\begin{array}{ll}\text { References } & 510\end{array}$ 


\title{
Demographic responses to short-term stress in $\mathbf{a}^{\text {th }}$ century Tuscan population: The case of household out-migration
}

\author{
Marco Breschi ${ }^{1}$ \\ Matteo Manfredini ${ }^{2}$ \\ Alessio Fornasin ${ }^{3}$
}

\begin{abstract}
This paper examines the relationship between household emigration and short-term crisis in a mid- $19^{\text {th }}$ century rural, Tuscan community. Based on a detailed reconstruction of individual and household life-histories, this study demonstrates the strong association between household emigration and different kinds of short-term stress, whether economic, epidemiologic, or household related. Despite some variations in response in relation to socioeconomic status (SES) - with the poorest strata of society more exposed to price changes and mortality crisis - the death of the household head is revealed as one of the most powerful overriding factors of household emigration.
\end{abstract}

\footnotetext{
${ }^{1}$ Department of Economics, University of Sassari, e-mail: breschi@uniss.it.

${ }^{2}$ Department of Genetics, Anthropology Evolution, University of Parma, e-mail: matteo.manfredini@unipr.it.

${ }^{3}$ Department of Economics and Statistics, University of Udine, e-mail: alessio.fornasin@dss.uniud.it.
} 


\section{Introduction}

This paper examines how $19^{\text {th }}$ century households reacted when their members endured periods of particular hardship, faced with events that could determine a sudden deterioration of economic conditions. Household emigration was a possible response, which, by implying the redefinition of not just one person's life but of an entire household's, was always difficult to foresee, control, and/or endure. This event undoubtedly represented one of the most significant key turning points in the lives of mid-19th century Italian villagers.

The relationship between the demographic behavior of past populations and shortterm stress has been widely investigated (see Bengtsson and Reher 1998 for an overview). Early studies adopt a macro-level approach, based on an econometric analysis of demographic, climatic, and economic data series and on large-scale populations (nations, regions, etc.). More recent research makes use of new statistical tools, focusing on individual life-histories, analyzed in the context of family and population dynamics. ${ }^{4}$ This paper adopts the latter, micro-level approach, focusing on household emigration response to short-term stress, such as economic crisis, epidemics, and internal family strains (such as the loss of the household head). A fair amount is known about individual and family responses to changes in climatic and economic conditions and demographic short-term stress in terms of survival (Bengtsson, Campbell, and Lee 2004; Derosas and Oris 2002), reproductive behavior (Tsuya et al. 2010), and matrimonial strategy. However, the migration response at both the individual and household level has been much less analyzed for historical Italy, mainly due to the lack of reliable sources recording people's movements both within and outside the municipality of residence before Italian unification in 1861 (CISP 1977; Corsini 1980). An uninterrupted and accurate recording of changes in residence only began in the 1930s. In addition, the few micro-level studies on mobility in the early post-unitary period are mostly restricted to individual migration (Hogan and Kertzer 1985; Kertzer and Hogan 1985).

A meticulous nominative linkage between different sources has made it possible to reconstruct the dynamics of both individual and household migrations between 1819 and 1859 for the rural population of Casalguidi, a community of the Grand Duchy of Tuscany. The mobility of rural populations has until now been largely explained in terms of rural-urban migration, especially in times of crisis, when towns and cities could be considered as places where it was easier to find support and assistance. Casalguidi would appear to represent a good case study of this phenomenon, given its

\footnotetext{
${ }^{4}$ See, among others, the comparative studies and volumes of the EurAsian Project on Population and Family History (EAP).
} 
proximity to Pistoia and Florence. However, considering that the process of industrialization and urbanization was in its early stages in Italy at the time, this paper suggests that the structure of land tenure also influenced the migration response of households in times of crisis rather than a straightforward rural-urban trajectory. Casalguidi was characterized by a large presence of landless people - mostly sharecroppers and agricultural day laborers - with different agricultural contracts that ensured various degrees of stability within the territory, and therefore diverse possible responses to short-term stress.

\section{Household out-migration. The Tuscan dichotomy: Sharecroppers and day laborers}

Unlike many other European societies where emigration was often a personal process representing the first step towards adulthood, such as in the case of life-cycle servant family formation systems (Laslett 1977, 1983; Dribe 2000; Szołtisek 2009; FauveChamoux and Wall 2005; Hajnal 1983; Viazzo 2004), in mid-19 $9^{\text {th }}$ century Tuscany outmigration was a decidedly household affair. A previous study on the Casalguidi community finds that over $53 \%$ of total emigration flows consisted of individuals emigrating along with the entire family group (Manfredini 2003). ${ }^{5}$

In this context, the limited occurrence of life-cycle servant-hood, the prevalence of patrilocal family formation systems, and the peculiarities of land tenure forms such as sharecropping, are likely to lie at the root of this household out-migration pattern.

The reasons behind the out-migration response of entire family groups and individuals would have differed considerably. Whereas individual mobility could be flexible, with movements back and forth in response to factors such as household strategies or work and marriage markets, household migration was more likely to be a traumatic event, triggered by crises of a different nature; namely, economic, sociopolitical, epidemiologic, or internal to the household itself.

The extent of the impact of these crises on out-emigration could vary according to degrees of precariousness and social insecurity. We can assume that households and families with low occupational and/or residential stability, few possessions, and a socially marginalized position were the most likely to leave in the event of short-term stresses. Therefore the first hypothesis of this study is that the households least rooted in the community had the highest risk of out-migrating.

\footnotetext{
${ }^{5}$ The rest are individual departures, of which marriage migrations represent around $7 \%$ of total out-migrations and $13 \%$ of individual ones.
} 
Two further factors which could play a role in this process are household size and composition (Angeli 1985; Corsini 1980). Small and simple households were advantaged since they could avail themselves of a more rapid decisional process in response to fluctuations in employment markets, and relocate with relative ease. Large and complex households, on the other hand, required a much longer decisional process, aggravated by the need to find suitable accommodation and a social context which ensured an income for most of its members. Large households were likely to opt for a process of family fission before resorting to the emigration of the entire group. However, small households were more vulnerable in certain circumstances, such as following the loss of the household head, when they could find themselves in the position of being unable to find a substitute to sustain the family income. Overall we can assume that the larger and more structured the household the lower the likelihood of out-migration, due to their greater ability to respond and adapt to internal and external stress factors.

Precariousness is also clearly linked to socioeconomic status, in that the poorer the household the higher its levels of instability and insecurity. Casalguidi, like the surrounding Tuscan countryside, was characterized by two important categories of landless farm laborers: sharecroppers and day laborers. This latter group was composed of extremely poor, unskilled, agricultural workers, often land and property-less and not involved in any form of land tenure, who continually moved around in search of seasonal or temporary work during periods of intense agricultural activity. No fixed abode meant no direct tie with the land; when the demand for agricultural labor fell in Casalguidi, day laborers could find employment in other unskilled activities or migrate towards other areas where the demand for seasonal work was higher.

The family work force was not the central factor for day laborers in finding or maintaining employment, and the frequent movements of this social category were not suited to large households with limited available resources (income, house, etc.). The family formation system of day laborers is accordingly characterized by early marriage, neolocality, and nuclear households (Breschi, Manfredini, and Pozzi 2004; Manfredini 2003; Manfredini and Breschi 2008).

The most representative socio-professional figure of rural Tuscany was the sharecropper. Sharecropping was a form of land tenure involving a usually annually renewed contract that provided for the halving of the farm's products and profits between the landowner and sharecropper. The household head took responsibility for the workforce, whilst the landowner (or his representative) was accountable for decisions concerning agricultural products and techniques (Giorgetti 1974; Pazzagli 1973). Although these contracts could vary significantly even within the same area, sharecropping remained the most common form of land tenure not only in the province 
of Pistoia but the whole of Tuscany during the $19^{\text {th }}$ century, maintaining its prominence even in a period that saw a rise in capitalism in agriculture (Giorgetti 1974).

The prosperity of sharecropping households was strongly qualified by a long and uninterrupted stay on the same farm, which in turn largely depended on striking the right balance between mouths to feed and the farm's resources. Household heads had the role of managing the household structure, creating a balance between male and female, active and non-active household members. Maintaining this equilibrium was not easy; births, deaths, illness, and the departure and arrival of members (especially women for marriage) meant the size and structure of the household was in a constant state of flux. This already difficult task was further complicated by the obligation to ensure an adequate crop for the landowner. This key contractual clause put sharecroppers under pressure to adopt specific demographic strategies to preserve an adequate work force within the household, such as higher fertility, the expulsion of less productive members, and a patrilocal arrangement for men after marriage. Well into the first half of the $20^{\text {th }}$ century the landlord still had the right to rescind the contract in the event of loss of a significant portion of the household work force (art. VI.d, Contract 1929). ${ }^{6}$ Variability in the number and composition of the sharecropping household was capable of creating problems in the relationship between landowner and sharecropper. This explains why strong rises in mortality could affect the household work force size enough to force the sharecroppers to leave. This was by no means a rare occurrence in an era still profoundly marked by high death rates and the recurrence of epidemics and famines. ${ }^{7}$ However, in the event of the household head's death alone, a landlord could soften his position if it was possible to somehow compensate for the unexpected loss of this key figure through finding a suitable replacement, usually a son or brother of the former household head. Other solutions were also possible, such as the arrival of extended family or the transfer of the household to a smaller farm. Sharecropping households generally struggled to avoid eviction and out-migration by implementing family strategies to safeguard from and soften the blow of even the most dramatic and traumatic events. Given the evidence of the permanence of many prosperous sharecropping households on the same farm over many generations, well rooted in the local community and supported by a strong kinship network, this system was clearly successful (Grilli 1997; Contini 2005).

From the above description, household migration can be linked to the concept of fragility. Economic precariousness, territorial instability, extraneity to the local

\footnotetext{
${ }^{6}$ The deadline for the rescission of the contract was August $31^{\text {st }}$, and at least five months notice had to be given prior to departure. This date relates to the agricultural year, which, in Pistoia, started on February $1^{\text {st }}$ and finished on January $31^{\text {st }}$. See Federazione Provinciale Sindacati Fascisti 1929.

${ }^{7}$ In Casalguidi, between 1800 and 1861, life expectancy at birth was slightly over 30 years, and we can count three major mortality crises $(1817,1833$, and 1855$)$.
} 
community, lack of a network of kin and relations, and limited human resources were all factors that increased the exposure of fragile households to the effects of short-term stress and hardship. Given this correlation, day laborers can be expected to have had the highest levels of mobility in Casalguidi.

However, migration was not necessarily always a negative, imposed event. It could also be a voluntary choice, taken by peasants (particularly sharecroppers and tenants) who simply had the possibility of better economic conditions elsewhere. This study hypothesizes that this 'positive' form of out-migration had a particularly important role in periods of mortality crisis, when surviving households would have gained greater contractual power over landlords, who were in need of replacements for decimated households.

\section{Sources, data, and the method used}

An examination of the relationship between household emigration and crisis at the individual and household level requires the collection of various kinds of data on economic, epidemiologic, and household-related factors. Regarding this period, this data must be retrieved from a number of both religious and civil sources, and then meticulously linked together. This process has made it possible to retrace the life histories of the inhabitants and households of Casalguidi between 1819 and 1859.

The population's demographic structure and evolution has been reconstructed using data from parish baptism, burial, and marriage registers, subsequently linked and then supplemented with information from the Status Animarum, an annually recorded census-like parish register that listed all the resident households within the parish territory, specifying the name, surname, age, sex, marital status, and relationship with the household head of each household member, including servants (Manfredini 1996). This integration of vital records and census data has allowed for the examination of one of the least studied demographic phenomena of historical societies, particularly in Italy: emigration. Given that there appears to be a complete lack of sources available for historical studies of this kind which contain direct, individual, and continuous information on migration, this research adopts an indirect approach. Out-migrants are taken as individuals who were recorded in the Stati Animarum at time $t$ but not at time $t+1$, and had not died (i.e., not recorded in the parish register of deaths). By extension, household emigration is considered as the absence at time $t+1$ of all components of the same household previously recorded at time $t$. 
This cross-checking of data between the Status Animarum and vital events parish registers has also allowed for an assessment of mortality levels year after year by calculating the Crude Death Rate (CDR). ${ }^{8}$

Four economic factors have been considered as economic variables: household head's occupation, family tax, house-ownership, and grain price. The first three define each household's yearly socioeconomic status. Information regarding occupation is available from both religious sources (Status Animarum and vital events registers) and civil registers of family taxes. The latter records information on each household head assessed as non-indigent and thus taxable according to wealth, including their name, surname, profession, and tax level (Manfredini and Breschi 2008). Information on occupation taken from the Status Animarum regards indigent household heads that were exempt from paying taxes, and therefore absent from the civil tax register. The linkage of these two sources (through household head's name and surname) provides not only a reliable picture of Casalguidi's overall socioeconomic structure, but also of the economic situation of each household. Although the tax system changed during this period, this paper considers three household tax groups: high/medium (the wealthiest), low (the poor), and exempt (the most indigent).

The Stati Animarum also allow for verifying if the household head owned the house of residence or not. However, this does not exclude the possibility that the family owned property in another part of Casalguidi, or indeed elsewhere. This information is extremely important for the purposes of this study, since it allows for a differentiation between sharecroppers and smallholders.

Data on grain prices is taken from previous studies by Bandettini (1957), using the average annual values recorded for the market of Florence. Pistoia's market prices are consistent with these, although systematically $8 \%$ lower, but it was decided to use the Florentine series since this dataset is more complete. ${ }^{9}$

We therefore constructed a longitudinal dataset including as many household observations for as many years as the household spent in Casalguidi. Each annual household record contains information at the household and community level (crude death rate and grain price). These are time-dependent variables that reflect the household structure and community context in any given year. The statistical tool best adapted to address longitudinal data with problems of truncation and censoring (Alter 1998) is Event History Analysis. Given the discrete nature of the reconstructed data, the

\footnotetext{
${ }^{8}$ No standardization has been applied on account of a certain stability of the age-structure of the population of Casalguidi in this pre-transitional period.

${ }^{9}$ Data on grain prices for Pistoia was taken from Comunità civica di Pistoia, "Registri dei prezzi delle grasce" and "Prezzi delle grasce", Pistoia State Archive.
} 
method employed to detect the impact of various short-term stressors on the likelihood of household out-migration is logistic regression (Bengtsson, Campbell, and Lee 2004).

\section{The parish of Casalguidi. Social structure and household out-migration}

The vast parish of S. Pietro in Casalguidi is a mere $8 \mathrm{~km}$ south of Pistoia and $35 \mathrm{~km}$ west of Florence (fig. 1). The plain, used to cultivate grains and other cereals, was the most densely populated area, whereas the least populated was the hills, characterized by vineyards and olive-groves (Chiti 1988). In this period S. Pietro in Casalguidi was the most populous parish of the Pistoia area, with an average of around 2,400 inhabitants, sustained by a significant growth rate of $5.8 \%$. In Casalguidi, as elsewhere in rural Tuscany, agriculture was by far the most important productive and economic sector, meaning that an extremely large proportion of the population struggled to find the necessary material resources for survival.

Figure 1: Geographical localization of Casalguidi

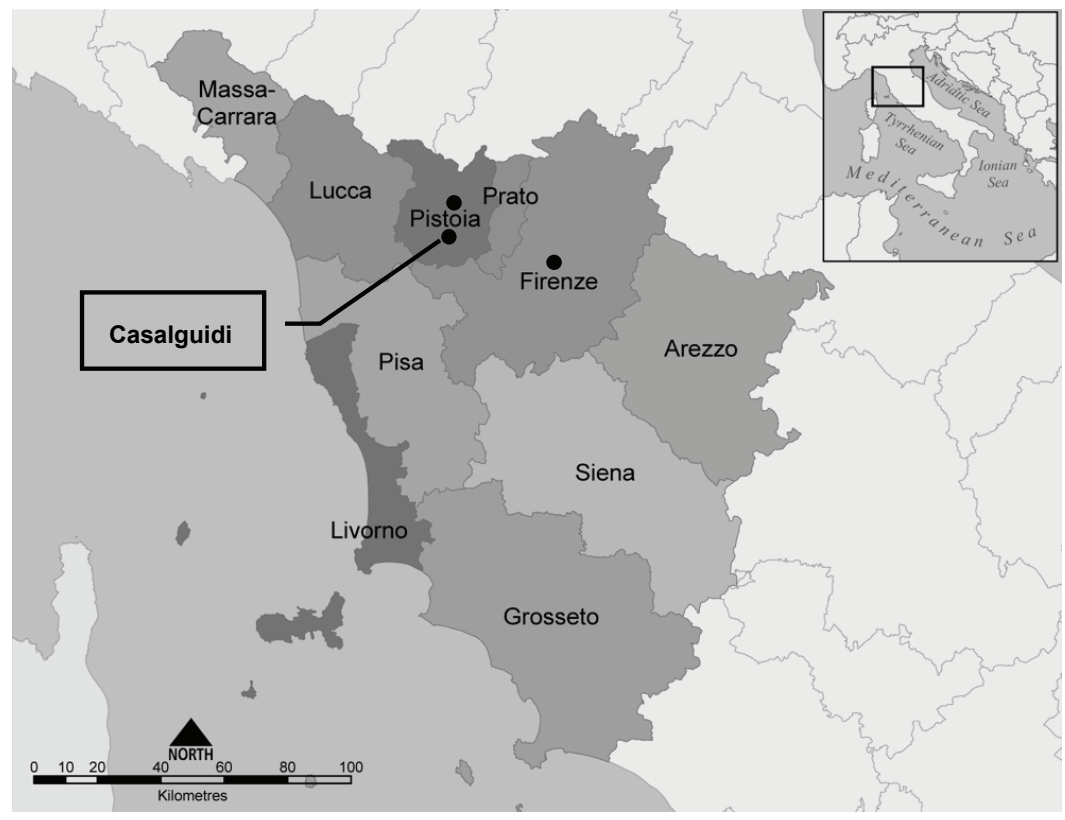


About $80 \%$ of both landed and landless farming households were involved in agricultural labor, resulting in a generally low-level of wellbeing. Over $50 \%$ of households fell into the minimum tax bracket, 35\% were exempt from payment for manifest indigence, around $13 \%$ were subject to high-medium taxes, and only $2 \%$ paid the highest contribution (Manfredini and Breschi 2008). Even among homeowners two out of ten households were exempt from taxes, which is a sign not only of the modest value of the property but above all of the difficulty they faced in providing for their own upkeep. The actual terms used for a household head exempt from taxes were "indigent and miserable". We can also note that the vast majority of households in Casalguidi with a female head, especially widows, were exempt from tax. Most of the population here, as in the rest of Tuscany, lived in a state of poverty that can be defined as structural. A sudden increase in the cost of living, serious health problems or, worse still, the premature death of the household head, and rising debts to the landowner were all capable of precipitating a household economic crisis. ${ }^{10}$

Figure 2 illustrates grain prices during the period. There is a peak in the biennium $1854-55$, when grain prices increased by $79 \%$, with a mean annual figure of $32.8 £ / q$.

\section{Figure 2: Crude mortality rate and grain price. Casalguidi, 1819-59}

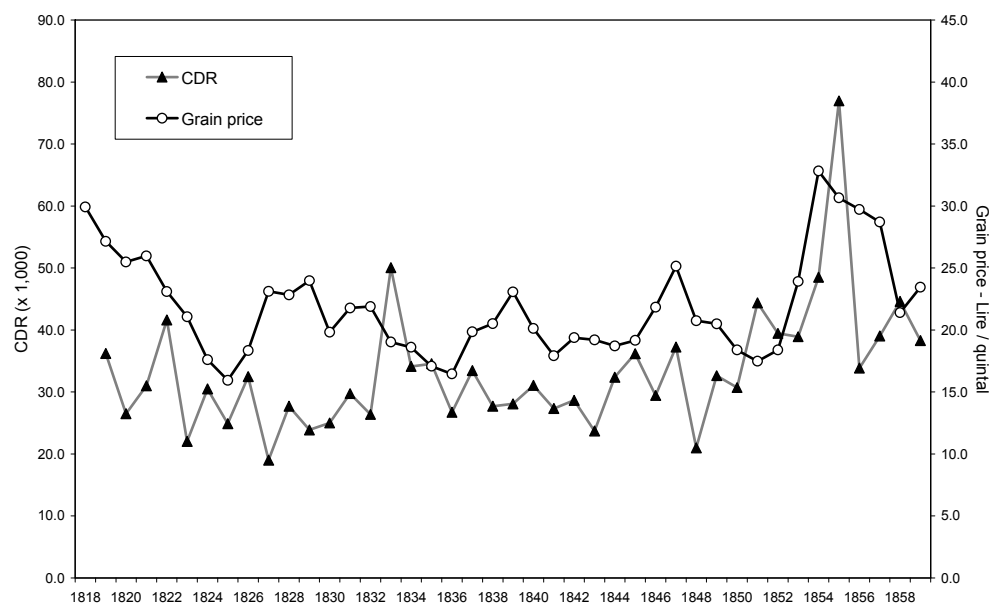

\footnotetext{
${ }^{10}$ On the incidence of mortality and economic crisis in Tuscany and Casalguidi see Breschi et al. 2010.
} 
This coincided with a serious cholera epidemic in the area which doubled the Crude Death Rate from 39 to 77 per thousand, the highest level for the entire period. However, the rise in grain price which peaked in August $1854(34.7 £ / q)$ would seem to have preceded the mortality crisis. In fact, the highest number of deaths was recorded exactly one year later, in August 1855, with 51 burials recorded by the parish priest.

Therefore 1854-55 represents the peak of both mortality and grain price in the period under study, which created the conditions for an increase in the mobility of individuals and households both within and beyond Casalguidi. Indeed, in 1855-56 household in- and out-migration rates peak at 60-70 per thousand, although netmigration is negative, around -10 per thousand (fig. 3).

A low level of net migration is characteristic of Casalguidi throughout this period. As Figure 3 demonstrates, household in- and out-migration rates were often quite close, with mean annual values over the entire period of 35.0 and 34.1 per thousand, respectively. The same can be seen for individual net migration: the population of Casalguidi gained an average of a mere six people a year. A similar, almost null net migration was also found for Casalecchio, another sharecropping community, in one of the very few individual-level studies on migration at the turn of the $20^{\text {th }}$ century by Kerzter and Hogan (1985). The limited role of migration in population growth in Casalguidi is also confirmed when looking at the single SES categories, both at the individual and household level.

\section{Figure 3: Household migration rates. Casalguidi, 1819-59}

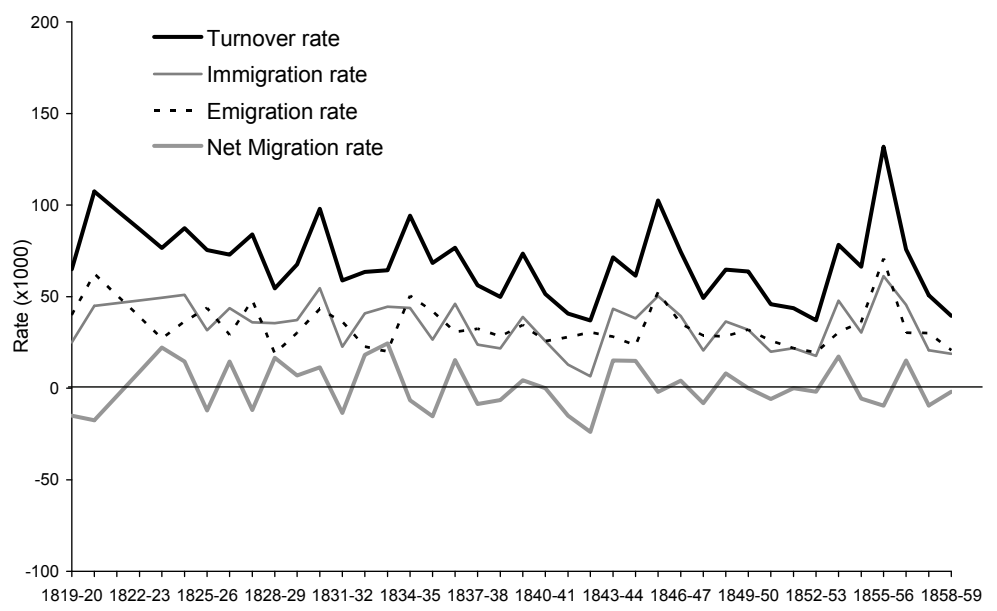


Net migration fluctuates very little, hovering around zero throughout the period (Table 1), for all the SES groups, although population increase does appear to be more associated with sharecroppers and day laborers than landed farmers. Small SES differentials are also a feature of return migration, which involved around $20-25 \%$ of individual departures in all the SES categories. This apparent absence of significant SES differentials in migration patterns suggests that the social structure of Casalguidi remained largely unaltered by migration. The prevalence of household over individual migration, the strong presence of return migration over short distances, and a balanced overall turnover are all features of a migration pattern hinged on movements within the countryside and less on rural-to-urban flows.

Table 1: $\quad$ Risk of household emigration. Casalguidi, 1819-58

\begin{tabular}{|c|c|c|c|c|c|}
\hline $\begin{array}{c}\text { House ownership / } \\
\text { Occupation }\end{array}$ & $\begin{array}{c}\text { At } \\
\text { risk }\end{array}$ & $\begin{array}{c}\text { Annual } \\
\text { mean } \\
\text { number of hh }\end{array}$ & $\begin{array}{c}\text { Emigration } \\
\text { rate } \\
(x 1,000)\end{array}$ & $\begin{array}{c}\text { Immigration } \\
\text { rate } \\
(\times 1,000)\end{array}$ & $\begin{array}{l}\text { Net migration } \\
\text { rate } \\
(\times 1,000)\end{array}$ \\
\hline Homeowners & 4,485 & 118 & 10.5 & 9.9 & -0.6 \\
\hline Non-homeowners & 12,302 & 324 & 35.4 & 39.7 & 4.3 \\
\hline Landed farmers & 3,052 & 80 & 10.5 & 9.4 & -1.1 \\
\hline Sharecroppers / Tenants & 8,239 & 217 & 31.3 & 36.9 & +5.6 \\
\hline Day laborers & 2,077 & 55 & 42.4 & 47.4 & +5.0 \\
\hline
\end{tabular}

Note: The number of at risk households is made up by household-years.

\section{Causes of household emigration. Role of different short-term stresses and differential responses by SES}

The relationship between household out-migration and short-term stress is assessed using a series of logistic regression models. ${ }^{11}$ The first is a preliminary model aimed at estimating the role of precariousness and instability on household out-migration, using as explanatory variables house-ownership, kinship network, tax level and household head's death as proxies for household internal stress (Table 2). Kinship network is defined as the presence of at least one household of relations in Casalguidi. The results confirm our hypothesis and demonstrate the extent to which these factors played a role in household emigration (see Table 2). House ownership, the presence of a kinship network, wealth, and absence of internal family problems all acted as elements of stability within the parish territory, thus sparing these households from out-migration.

${ }^{11}$ One-person households and houses with unknown ownership were excluded. 
The risk of household out-emigration is three times higher for non-homeowners than for homeowners. The lack of a kinship network doubles the risk of household outmigration. High/medium-tax and low-tax households ran a $63 \%$ and $43 \%$ (respectively) lower risk of leaving Casalguidi compared to those exempt from tax. The loss of the household head emerges as a dramatic short-term stress factor, increasing the likelihood of household out-migration by almost four times.

Table 2: $\quad$ Risk of household emigration. Casalguidi, 1819-58

\begin{tabular}{|c|c|c|c|c|c|}
\hline Covariates & Freq. & RR & p-val & RR & p-val \\
\hline House-ownership (ref. homeowner) & 26.7 & 1.000 & & 1.000 & \\
\hline Non-homeowner & 73.3 & 2.863 & 0.000 & 3.149 & 0.000 \\
\hline Kinship network (ref. No) & 82.0 & 1.000 & & 1.000 & \\
\hline Yes & 17.7 & 0.475 & 0.000 & 0.475 & 0.000 \\
\hline Household Tax (ref. Tax exempt) & 33.4 & 1.000 & & 1.000 & \\
\hline Highest/Medium Tax & 13.1 & 0.370 & 0.000 & 0.366 & 0.000 \\
\hline Low Tax & 53.5 & 0.573 & 0.000 & 0.572 & 0.000 \\
\hline Household head death within the year (ref. No) & 97.9 & 1.000 & & 1.000 & \\
\hline Yes & 2.1 & 3.766 & 0.000 & 8.847 & 0.000 \\
\hline hh's death*house-ownership & & & & 0.358 & 0.035 \\
\hline Log likelihood & -2092.3 & & & -2090.3 & \\
\hline Total number of household-years & 16,787 & & & & \\
\hline Likelihood Ratio test & \multicolumn{5}{|c|}{$\chi^{2}=195.1 ; p-$ val $=0.046$} \\
\hline
\end{tabular}

Note: the model controls for the sex of the household head. RR = Relative risk.

Figure 4 demonstrates that this event had a huge effect regardless of house ownership (see also Table 3 below). ${ }^{12}$

House ownership emerges as one of the strongest indicators of stability and territorial ties, which acted as a powerful disincentive to emigration. Not owning the house where one lived usually also implied being landless. Property owning families tended to live in the same house for generations, with the occasional departure of a few household members. Property-less families were more likely to move en masse, possibly forced by the homeowner. Given the large differential risk that emerges above and the intrinsically different characteristics of the homeowner versus non-homeowner group, particularly regarding ties with the land, it was decided to run different sets of

\footnotetext{
${ }^{12}$ The relative risks used in Figure 4 were calculated as follows. The new reference category is formed by the reference categories of the two factors involved (Homeowner and Household head alive) and takes the value of 1 . The relative risk for the category Non-homeowner is now the effect of being non-homeowner when the other factor in the interaction term is at the reference category (3.149). Similarly, 8.847 is the relative risk expressing the effect of household head's death when the other variable is Homeowner. Finally, the effect of being non-homeowner in presence of household head's death is given by the product of the two previous relative risks with the interaction term $(3.149 * 8.847 * 0.358)$.
} 
models for each category, with the aim of checking for possible differential migration responses to economic, mortality, and internal family crises.

Figure 4: Relative risks of the interaction house-ownership-household head's death

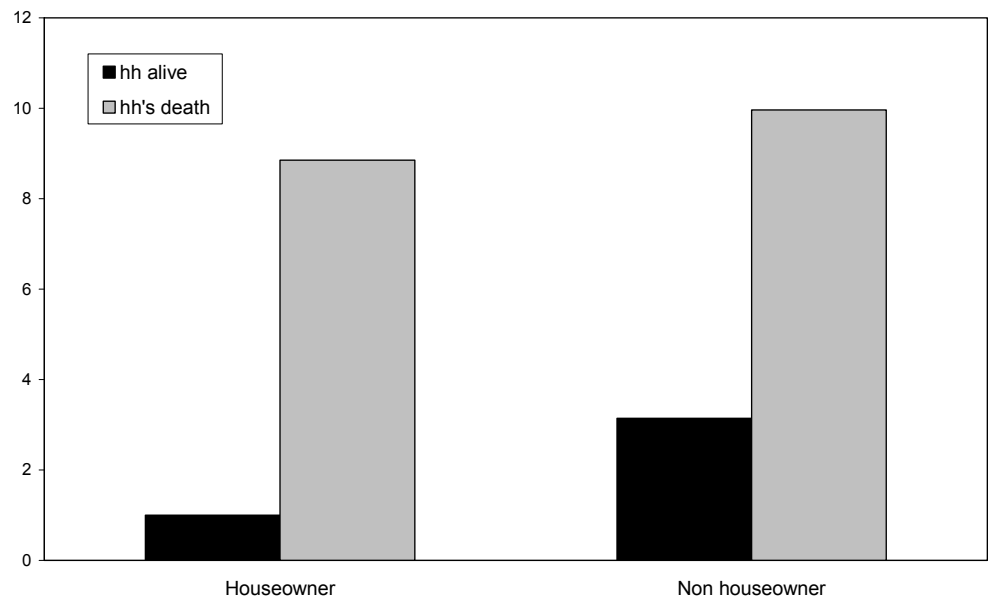

The economic situation was assessed through grain price, by means of deviation from the trend, calculated using a filtering process (Bengtsson and Brostrom 2009). The mortality level was measured using the Crude Death Rate, and death of the household head was used as a proxy of internal family stress. These results are presented below (Table 3).

Table 3: Risk of household emigration by economic, mortality, and household short-term stress. Casalguidi, 1819-58

\begin{tabular}{|c|c|c|c|c|c|c|}
\hline \multirow[t]{2}{*}{ Covariates } & \multicolumn{3}{|c|}{ Homeowner } & \multicolumn{3}{|c|}{ Non-homeowner } \\
\hline & Mean & $\mathbf{R R}$ & p-val & Mean & $\mathbf{R R}$ & p-val \\
\hline Grain price & -0.012 & 0.645 & 0.672 & -0.011 & 2.169 & 0.031 \\
\hline Crude death rate & 33.6 & 1.001 & 0.965 & 33.6 & 1.008 & 0.062 \\
\hline Household head death within the year (ref. No) & 97.6 & 1.000 & & 98.0 & 1.000 & \\
\hline Yes & 2.4 & 8.559 & 0.000 & 2.0 & 3.023 & 0.000 \\
\hline Log likelihood & -246.6 & & & -1836.8 & & \\
\hline Total number of household-years & 4,485 & & & 12,302 & & \\
\hline
\end{tabular}

Note: the model controls for kinship network, tax level, and sex of the household head. 
Findings reveal that whereas the risk of household out-emigration for homeowners remained largely unaffected by short-term economic stress, for non-homeowners it rose. Clearly, the weakest and poorest members of the population were the hardest hit by the effects of short-term economic stress. A deterioration of economic conditions meant that landless farmers, day laborers, and poor artisans were more likely to search elsewhere for alternative work opportunities or better working conditions.

The risk of household emigration for non-homeowners also rises in response to increases in mortality, while there is no significant change for homeowners. Regarding mortality, the out-migration of non-house-owning households could be elicited by two almost opposite situations. Firstly, during periods of high mortality these households could lose several members, to the point of no longer being able to manage the farm or pay their rent, consequently being forcibly evicted by the landlord. Secondly, from a purely supply and demand viewpoint, households little affected by mortality crisis found themselves in an extremely favorable position and were able to take advantage of the consequential increased number of vacant farms. In these circumstances the offer of better economic conditions elsewhere could induce some peasant families to up and move.

The results for death of the household head are dramatic for all households regardless of home ownership, increasing the likelihood of leaving Casalguidi by three to seven times. ${ }^{13}$ Evidently this event represented a moment of great stress for many peasant families. The loss of this figure necessitated a difficult process of internal restructuring and reorganization, with the primary objective of finding a suitable replacement. This task could be particularly difficult and even insurmountable in the absence of adult males within the household, in which case the family was left without a guide who managed the household, earned money, took and implemented decisions, and signed legal contracts. This was true for both landless and landed families, who were also faced with questions of inheritance. Indicatively, five of the seven house owning households to have emigrated following the death of the household head were so small as to lack an adult male. Accordingly, a further variable was introduced to the model, namely the presence in the household of at least one adult male over 21 years at the time of the household head's death (Table 4). ${ }^{14}$ Results are in line with previous expectations. The presence of an adult male over the age of 21 largely and significantly decreases the risk of household out-migration in the event of the household head's death. However, the results of interactions (Fig. 5) demonstrate that the protective effect

\footnotetext{
${ }^{13}$ It is worth noting, however, that the variability of coefficients for this covariate is also due to the small number of observations in the various categories.

${ }^{14}$ In other words, we have checked for the presence of an adult male kin $21+$ years in the last Status Animarum where the household head was reported still alive.
} 
of the presence of an adult male 21+ is effective and significant only in landless households, where it neutralizes the disruptive consequences of the household head's death capable of leading to household departure. ${ }^{15}$

Table 4: $\quad$ Risk of household emigration by short-term economic, mortality, and household stress. Model with interaction. Casalguidi, 1819-58

\begin{tabular}{lcccccc}
\hline Covariates & \multicolumn{3}{c}{ Homeowner } & \multicolumn{3}{c}{ Non homeowner } \\
& Mean & RR & p-val & Mean & RR & p-val \\
\hline Grain price & -0.012 & 0.669 & 0.702 & -0.011 & 2.131 & 0.035 \\
Crude death rate & 33.6 & 1.001 & 0.947 & 33.6 & 1.008 & 0.069 \\
Household head death within the year (ref. No) & 97.6 & 1.000 & & 98.0 & 1.000 & \\
Yes & 2.4 & 15.327 & 0.000 & 2.0 & 5.839 & 0.000 \\
Presence of an adult male 21+ yrs (ref. No) & 57.4 & 1.000 & & 58.1 & & \\
Yes & 42.6 & 1.084 & 0.819 & 41.9 & 1.079 & 0.476 \\
Interaction hh's death ${ }^{*}$ Presence of M 21+ & & 0.257 & 0.153 & & 0.187 & 0.002 \\
Log likelihood & -245.4 & & & -1830.9 & & \\
Total number of household-years & 4,485 & & & 12,302 & & \\
\hline
\end{tabular}

Note: the model controls for kinship network, tax level, and sex of the household head.

At this point a more in-depth examination of the responses of different categories of farmers and agricultural labourers to short-term stress is needed. The category of non-homeowners includes both sharecroppers and day labourers, despite the fact that they differ in many respects. Sharecroppers have more in common with smallholders in terms of household structure and residence after marriage, so the Table 3 model was applied separately to smallholders, day labourers, and sharecroppers (Table 5).

\footnotetext{
${ }^{15}$ This is also confirmed by the Likelihood ratio test applied to test the increase in the explanatory power of the model with interaction term compared to the model without it. For homeowners, it is non-significant $\left(\chi^{2}=\right.$ $2.3 ; \mathrm{p}$-val $=0.128)$, whereas it shows a significant increase in the model concerning non-homeowners $\left(\chi^{2}=\right.$ 11.7; $\mathrm{p}$-val $=0.001$ ). However, as already stated in footnote 10 , the absence of statistical significance for the homeowner group could be due to the limited size of the sub-group of households with an adult male 21+ years and whose head had died. This presence could have some effect on both groups.
} 


\section{Figure 5: Relative risks of the interaction house-ownership-household head's death}

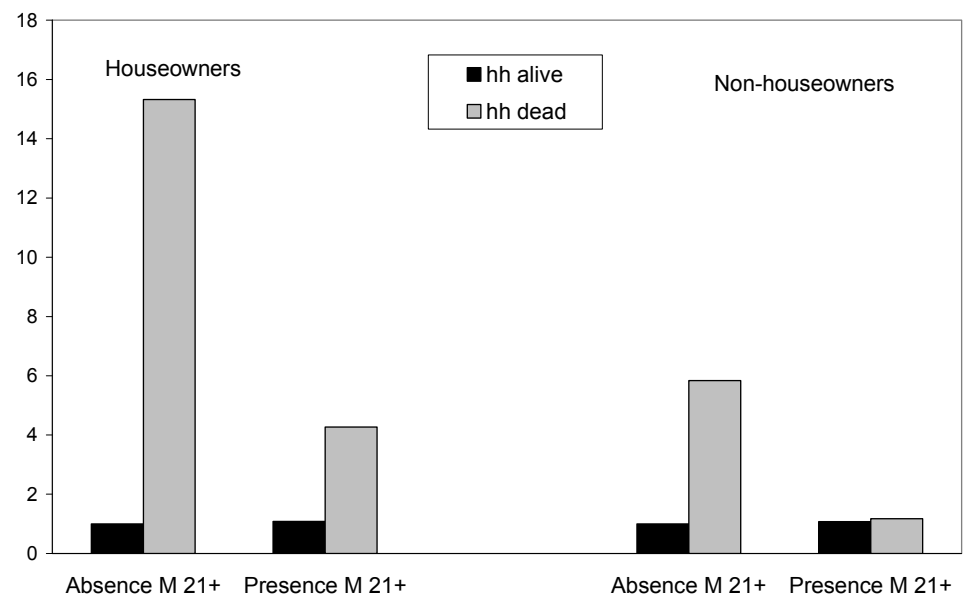

The effect of the death of the household head is the sole element that the three response patterns have in common. Regardless of social group, the loss of the household head appears to be the one decisive element that contributed heavily to the out-migration of all household types, despite considerable differences in motivation. In the case of landed households with the highest coefficients, we can hypothesize the coming into play of inheritance issues. Women generally inherited property only when there were no other possible male-line heirs, meaning that a widow's family was often forced to give up the house and farm to relatives and out-migrate. It is also possible that the widow was not capable of managing the farm and chose to leave, prompting the arrival of relatives who were able to fulfill the task (see also footnote 10).

Landed farmers, most of which are smallholders, appear to be sensitive to the household head's death alone. Neither economic nor mortality crisis were capable of inducing these households to migrate, denoting their high degree of stability and tight bonds with the local territory. Conversely, landless households are sensitive to a wider range of short-term stresses, besides the household head's death. Results indicate a dichotomy between day laborers and sharecroppers, with the latter more likely to migrate in response to increases in overall mortality levels and the former in response to price fluctuations. 
Table 5: Risk of household emigration by short-term economic, mortality, and household stress. Model without interaction. Casalguidi, 1819-58

\begin{tabular}{lccccccccc}
\hline \multicolumn{1}{c}{ Covariates } & \multicolumn{3}{c}{ Landed farmers } & \multicolumn{3}{c}{ Sharecroppers } & \multicolumn{3}{c}{ Day Laborers } \\
& Mean & RR & p-val & Mean & RR & p-val & Mean & RR & p-val \\
\hline Grain price & -0.012 & 0.818 & 0.873 & -0.011 & 0.979 & 0.962 & -0.013 & 6.777 & 0.028 \\
Crude death rate & 33.6 & 0.995 & 0.804 & 33.4 & 1.011 & 0.045 & 34.9 & 1.004 & 0.676 \\
Hh's death within the year (ref. No) & 98.2 & 1.000 & & 98.1 & 1.000 & & 97.7 & 1.000 & \\
Yes & 1.8 & 8.773 & 0.000 & 1.9 & 2.019 & 0.049 & 2.3 & 3.489 & 0.009 \\
Presence of a male 21+ yrs (ref. No) & 59.3 & 1.000 & & 52.5 & 1.000 & & 74.6 & 1.000 & \\
Yes & 40.7 & 0.896 & 0.784 & 47.5 & 0.749 & 0.030 & 25.4 & 0.753 & 0.299 \\
\hline Log likelihood & -172.1 & & & -1140.4 & & & -323.4 & \\
Total number of household-years & 3,052 & & & 8,239 & & & 1,766 & \\
\hline
\end{tabular}

Note: the model controls for kinship network, tax level, and sex of the household head.

This is to be expected, since day laborers were forced to rely on the local market for all necessary goods, meaning their living conditions depended closely on the local economic situation. In periods of high prices day laborers not only saw a decrease in their real wages, but also had fewer employment opportunities in the agricultural sector due to falling demand for a labor force, forcing them to look elsewhere. Sharecroppers, however, cultivated and consumed their own produce and were therefore much less affected by price increases. The results do show sharecroppers as sensitive to mortality crisis, namely the cholera epidemic of 1854-55. In these two years the mean size of the 23 households that out-migrated was 4.4 members, whereas for those who remained it was around $6^{16}$. Nevertheless, this differential does not result from cholera alone (only 5 out of the 23 emigrating households had suffered one or more deaths from 1854-55). The high mortality rate, in having changed the size of a number of sharecropping households, possibly prompted landlords to 'reshuffle' households, moving them to farms more apt to their 'new' dimensions (Grilli 1997). The importance of the role of size and structure of sharecropping households in terms of protection from crisis is confirmed by the fact that the presence of adult males significantly decreased the risk of household out-migration. As mentioned, this was an especially decisive factor in determining response to the event of the household head's death (Table 6).

\footnotetext{
${ }^{16}$ A model excluding the cholera epidemic, not shown here, reveals a weaker relationship between mortality and household out-migration.
} 
Table 6: Risk of household emigration by short-term economic, mortality, and household stress. Model with interaction. Casalguidi, 1819-58

\begin{tabular}{|c|c|c|c|c|c|c|}
\hline \multirow[t]{2}{*}{ Covariates } & \multicolumn{3}{|c|}{ Landed farmers } & \multicolumn{3}{|c|}{ Sharecroppers \& tenants } \\
\hline & Mean & $\mathbf{R R}$ & p-val & Mean & $\mathbf{R R}$ & p-val \\
\hline Grain price & -0.012 & 0.813 & 0.874 & -0.011 & 0.878 & 0.774 \\
\hline Crude death rate & 33.6 & 1.002 & 0.942 & 33.4 & 1.012 & 0.049 \\
\hline Household head death within the year (ref. No) & 40.7 & 1.000 & & 98.1 & 1.000 & \\
\hline Yes & -0.012 & 14.773 & 0.000 & 1.9 & 4.836 & 0.001 \\
\hline Presence of an adult male $21+y r s$ (ref. No) & 33.6 & 1.000 & & 52.5 & 1.000 & \\
\hline Yes & 98.2 & 1.302 & 0.511 & 47.5 & 0.928 & 0.590 \\
\hline Interaction hh's death*Presence of M 21+ & & 0.249 & 0.294 & & 0.196 & 0.029 \\
\hline Log likelihood & -166.9 & & & -1125.0 & & \\
\hline Total number of household-years & 3,052 & & & 8,239 & & \\
\hline Likelihood Ratio test & \multicolumn{3}{|c|}{$\chi^{2}=1.4 ; p-v a l=0.245$} & \multicolumn{3}{|c|}{$\chi^{2}=5.1 ; p-v a l=0.023$} \\
\hline
\end{tabular}

Note: The model controls for kinship network, tax level, and sex of the household head. The LR test was used to check the variation in log-likelihood between models in Table 5 and those in Table 6.

Being able to find an immediate substitute for the former household head meant that sharecropping households had someone to take charge of signing contracts and responsibility for running the farm. In contrast, this effect was not significant for smallholders, whose household structure was an element of less importance and unconnected to contractual relationships. ${ }^{17}$

Lastly, the predicted migration percentage change of the three socio-occupational categories was computed, using the sole significant variables in Table $5,{ }^{18}$ to provide a conclusive and comprehensive picture of their different migration patterns. The results, shown in Table 7, refer to the worst and best case scenarios in relation to grain price, mortality rate, death of the household head, and absence of any adult male aged $21+$.

Table 7: Predicted percentage change of household out-migration by socio-occupational category and scenario

\begin{tabular}{lcc}
\hline SES & Good scenario & Bad Scenario \\
\hline Landed farmers & 1.0 & 7.3 \\
Sharecroppers & 2.2 & 8.4 \\
Day laborers & 3.4 & 21.1 \\
\hline
\end{tabular}

The likelihood of out-migrating in 'good times' was evidently low for all the SES groups, regardless of their ties with the land or form of land tenure. This situation dramatically changes in 'bad times'. In this case the chances of out-migration of both

\footnotetext{
${ }^{17}$ The model for day laborers was not estimated due to a lack of events in the interaction term.

${ }^{18}$ Table 5 was used because it includes all three SES groups.
} 
landed farmers and sharecroppers does rise, although this remains quite low in absolute terms (below 9\%), again proving the substantial similarity of sharecroppers and smallholders in terms of stability. Day laborers, however, present a high probability of out-migration during troubled times (one out of five households), which reflects their weaker ties with the territory, reduced stability, and fragile socioeconomic condition.

\section{Conclusions}

Internal migration in historical Italy is often explained in terms of rural-to-urban mobility. This demographic mechanism is held to gain particular importance in moments of crisis, when poor and landless peasants flocked towards towns and cities in the hope of finding better opportunities. From this point of view the decisive factor in preventing emigration was the possession of a house and (even small) plots of land.

The reality of the mid $19^{\text {th }}$ century Tuscan community taken as the case study for this research proves to be much more complex, and only partially supports the above assumptions. Household (and individual) emigration in Casalguidi does not at any time in the period examined, even during the cholera epidemic of 1855 , resemble a massive exodus of people fleeing the countryside, but rather an ordinate and balanced movement of households both in and out of the community. The high degree of return migrations for all SES groups suggests the existence of short-distance, circular movements between Casalguidi and surrounding areas, rather than a direct rural-to-urban transfer.

Nevertheless, household emigration does appear to be strongly affected by factors of short-term stress, against which house-ownership, high SES, economic resources, and kinship networks formed a protection by creating stability and ties with the local territory. The poorest and landless sectors of the population, namely day laborers, unskilled farmers, and indigent people, not surprisingly emerge as the most fragile and precarious. Day laborers in particular, by having no direct ties with the land and being ever exposed to the volatility of market prices, were the hardest hit by the effects of short-term economic stress, and therefore the most likely to migrate.

Sharecroppers, however, despite being landless and non-homeowners, emerge as a much less fragile and unstable social category. In being a unit of autonomous production and consumption they were relatively unresponsive (in terms of mobility) to short-term economic stress. Sharecroppers' risk of household out-migration does increase in the presence of a mortality crisis (Breschi et al. 2010), but this could also be a reflection of voluntary choices prompted by the chance of securing better economic conditions elsewhere on one of the increased number of available farms. In short, the degree of rootedness of sharecroppers in the community of Casalguidi differs very little from that of smallholders and landed inhabitants. 


\section{References}

Alter, G. (1998). L'event history analysis en démographie historique. Difficultés et perspectives. Annales de Démographie Historique 2: 25-35.

Angeli, A. (1985). Ricerca sulla mobilità della popolazione a metà '800 nel Bolognese. In: SIDES (ed.). La popolazione italiana nell'Ottocento. Continuità e mutamenti. Bologna: Clueb: 357-388.

Bandettini, P. (1957). I prezzi sul mercato di Firenze dal 1800 al 1890. ILTE: Turin.

Bengtsson, T. and Brostrom, G. (2009). Do conditions in early life affect old-age mortality directly and indirectly? Evidence from 19th-century rural Sweden. Social Science and Medicine 68(9): 1583-1590. doi:10.1016/ j.socscimed.2009.02.020.

Bengtsson, T., Campbell, C., and Lee, J.Z. (2004). Life under pressure: Mortality and living standards in Europe and Asia, 1700-1900. Cambridge: Massachusetts Institute of Technology Press.

Bengtsson, T. and Reher, D. (1998). Short and medium term relations between population and economy. In: Nuñes, C.-E. (ed.). Debates and Controversies in Economic History. Proceedings of the Twelfth International Economic History Congress. Madrid: Fundacíon Ramón Areces e Fundacíon Fomento de la Historia Económica.

Breschi, M., Fornasin, A., Gonano, G., Manfredini, M., and Seghieri, C. (2010). Demographic responses to short-economic stress in a $19^{\text {th }}$-century Tuscan population. In: Kurosu, S., Bengtsson, T., and Campbell, C. (eds.). Demographic responses to economic and environmental crises. Proceedings of the IUSSP Seminar. Kashiwa: Reitaku University: 48-64.

Breschi, M., Manfredini, M., and Pozzi, L. (2004). Mortality in the first years of life: Socio-economic determinants in an Italian nineteenth-century population. In: Breschi, M. and Pozzi, L. (eds.). The determinants of infant and childhood mortality in Europe during the last two centuries. Forum: Udine: 123-138.

Chiti, M. (1988). Casalguidi nel tempo. Piccola storia di un mondo scomparso con testimonianze di vita vissuta dai protagonisti. Pistoia: Tipografica Pistoiese.

CISP - Comitato Italiano per lo Studio della Demografia Storica (1977). Problemi di utilizzazione delle fonti di demografia storica. Roma. 
Contini, G. (2005). Aristocrazia contadina. Sulla complessità della società mezzadrile. In: Fattorie, famiglie, individui. Siena: Protagon Editori.

Corsini, C.A. (1980). La mobilità delle popolazioni nel Settecento: fonti, metodi problemi. La popolazione italiana nel Settecento. Bologna: Clueb.

Derosas, R. and Oris, M. (2002). When dad died. Individuals and families coping with distress in past societies. Bern, Berlin, Bruxelles, Frankfurt/M., New York, Oxford, Wien: Peter Lang.

Dribe, M. (2000). Leaving home in a peasant society. Economic fluctuations, household dynamics and youth migration in Southern Sweden, 1829-1866. Södertälje: Almqvist \& Wiksell International.

Fauve-Chamoux, A. and Wall, R. (2005). Domestic servants in comparative perspective. The History of the Family: An International Quarterly 10(4).

Federazione Provinciale Sindacati Fascisti Agricoltori e Unione Provinciale Sindacati Fascisti dell'Agricoltura di Pistoia (1929). Contratto collettivo di lavoro per la conduzione di Fondi Rustici a Mezzadria nella Regione Toscana concordato in Firenze addì 21 Dicembre 1928 - Anno VII e Patti aggiunti per la Provincia di Pistoia. Florence: Stabilimento Tipografico G. Ramella \& C.

Giorgetti, G. (1974). Contadini e proprietari nell'Italia moderna. Rapporti e contratti agrari dal secolo XVI a oggi. Turin: Einaudi.

Grilli, S. (1997). Il tempo genealogico. Le famiglie dei mezzadri in una fattoria Toscana. Turin: L'Harmattan Italia.

Hajnal, J. (1983). Two kinds of pre-industrial household formation system. In: Wall, R., Robin, J., and Laslett, P. (eds.). Family Forms in Historic Europe. Cambridge: Cambridge University Press.

Hogan, D.P. and Kertzer, D.I. (1985). Migration patterns during Italian urbanization, 1865-1921. Demography 22(3): 309-325. doi:10.2307/2061063.

Kertzer, D.I. and Hogan, D.P. (1985). On the move: Migration in an Italian community, 1865-1921. Social Science History 9(1): 1-23. doi:10.2307/1170916.

Laslett, P. (1977). Family life and illicit love in earlier generations. Cambridge: Harvard University Press. doi:10.1017/CBO9780511522659.

Laslett, P. (1983). Family and household as work group and kin group: Areas of traditional Europe compared. In: Wall, R. (ed.). Family forms in historic Europe. Cambridge: Cambridge University Press: 513-564. 
Manfredini, M. (1996). L'utilizzo degli status animarum nelle ricostruzioni nominative: Miglioramenti informativi qualitativi e quantitativi. Il caso di Madregolo (16291914). Bollettino di Demografia Storica 24/25: 113-129.

Manfredini, M. (2003). Families in motion: The role and characteristics of household migration in a 19th-century rural Italian parish. The History of the Family: An International Quarterly 8(2): 317-343.

Manfredini, M. and Breschi, B. (2008). Socioeconomic structure and differential fertility by wealth in a mid-nineteenth century Tuscan community. Annales de Demographie Historique 1: 15-33.

Pazzagli, C. (1973). L'agricoltura toscana nella prima meta dell'800: tecniche di produzione e rapporti mezzadrili. Florence: Olschki.

Szołtisek, M. (2009). Life cycle service and family systems in the rural countryside: A lesson from historical east-central Europe. Annales de démographie historique 117(1): 53-94.

Tsuya, N.O., Feng, W., Alter, G., and Lee, J.Z. (2010). Prudence and pressure. Reproduction and human agency in Europe and Asia, 1700-1900. Cambridge: Massachusetts Institute of Technology Press.

Viazzo, P.P. (2004). Family structures and the early phase in the individual life cycle. A southern European perspective. In: Henderson, J. and Wall, R. (eds.). Poor women and children in the European past. London: Routledge: 31-50. 